Int. J. Electrochem. Sci., 15 (2020) $696-709$

\title{
Enhanced Electrokinetic Remediation of Heavy-Metals Contaminated Soil in presence tetrasodium N,N- bis(carboxymethyl) glutamic acid (GLDA) as chelator
}

\author{
Xiaojuan Yang ${ }^{1}$, Mingzhu Zhou ${ }^{2}$, Long Cang ${ }^{2, *}$, Qiaowei Ji ${ }^{1}$, Jiye Xie ${ }^{1}$ \\ ${ }^{1}$ Power China Huadong Engineering Corporation Limited, Hangzhou 311122, China; \\ ${ }^{2}$ Key Laboratory of Soil Environment and Pollution Remediation, Institute of Soil Science, Chinese \\ Academy of Sciences, Nanjing 210008, China) \\ ${ }^{*} \mathrm{E}$-mail: canglong@issas.ac.cn
}

doi: $10.20964 / 2020.01 .15$

Received: 6 August 2019 / Accepted: 17 September 2019 / Published: 30 November 2019

\begin{abstract}
Electrokinetic remediation (EK) is an emerging method that is used to decontaminate soil contaminated with heavy metals. Heavy metal removal rates can be enhanced by applying chelators to the soil; however traditional chelators have shortcomings, such as poor biodegradability (EDTA, DTPA, etc.), high cost (EDDS, etc.), and low complexing abilities (citric acid, NTA, etc.). In this study, we used tetrasodium N,N-bis(carboxymethyl) glutamic acid (GLDA), a novel and cheap biodegradable chelator to enhance the electrokinetic remediation of a heavy metals-contaminated soil. The batch extraction experiments used three types of biodegradable chelators (latic acid, citric acid, and GLDA) and four EK tests (T1: catholyte controlled at $\mathrm{pH} 4$ without GLDA; T2: only GLDA; T3: bipolar electrolyte controlled at pH 6 with GLDA; T4: cation and anion exchange membranes with GLDA) were conducted. The batch experiments showed that the $\mathrm{Cu}$ and $\mathrm{Ni}$ extraction rates for GLDA (39\% to $48 \%)$ were higher than for citric acid (26\% to $41 \%)$ and latic acid $(0.44 \%$ to $25 \%)$, and the solution $\mathrm{pH}$ had little effect on the GLDA extraction rate. The EK experiments showed that the T3 and T4 treatments had little effect on soil pH and EC. However, T1 greatly decreased soil $\mathrm{pH}$ and increased soil EC. A total of $12.9 \%-20.1 \% \mathrm{Cu}$ and $24.8 \%-27.7 \% \mathrm{Ni}$ were removed from the soil after 8 days of the T3 and T4 treatments. Those removal rates were higher than those obtained with the $\mathrm{T} 1$ and $\mathrm{T} 2$ treatments. The total $\mathrm{Cr}$ removal rates in all treatments were very low $(1.55 \%$ to $5.70 \%)$, which could be due to the high percentage of the residual $\mathrm{Cr}$ form. The results for energy consumption indicated that $\mathrm{T} 4$ had the lowest energy consumption (19.3 $\mathrm{kWh}^{-1}$ ). Therefore, installing cation and anion exchange membranes could increase $\mathrm{Cu}$ and Ni removal rates and decrease energy consumption. Furthermore, GLDA could potentially be used during the EK remediation of soil contaminated with heavy metals.
\end{abstract}

Keywords: Electrokinetic remediation; GLDA; Heavy metal; Ion exchange membrane; pH control 
(C) 2020 The Authors. Published by ESG (www.electrochemsci.org). This article is an open access article distributed under the terms and conditions of the Creative Commons Attribution license (http://creativecommons.org/licenses/by/4.0/). 